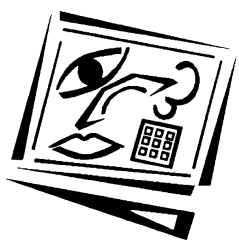

\title{
Examining facilitators' habits of mind in an asynchronous online discussion environment: A two cases study
}

\author{
Wing Sum Cheung and Khe Foon Hew \\ Nanyang Technological University
}

\begin{abstract}
Asynchronous online discussion has been widely used by faculty members and students in schools and universities. Previous research has examined how factors such as the discussion activity, knowledge about the discussion topic, and the behaviour of other participants can affect learner participation. This study explored student facilitators' influence in promoting learners' participation in terms of their exhibited habits of mind. The following habits of mind of the facilitators were examined: (a) awareness of own thinking, (b) accurate and seeks accuracy, (c) open minded, (d) taking a position when the situation warrants it, and (e) sensitive to other. A two-cases study methodology approach was used in this study. The habits of "awareness of own thinking" and "open minded" were found to be exhibited more often by the student facilitators in the two cases. When we zoomed into the top $30 \%$ of the forums in terms of learners' participation, we also found that the frequency of habits of mind, "awareness of own thinking" and "open minded", were exhibited more often by the facilitators.
\end{abstract}

\section{Introduction}

In the last decade, e-learning has become more and more popular in many schools and universities. Some educators and scholars use other terms such as "web based learning" and "online learning" to describe e-learning. According to Harmon and Jones (2000), web based learning could be divided into five levels. The highest level (i.e., level five) allows all teachers and students to have online discussions. There are basically two types of online discussions: synchronous online discussion and asynchronous online discussion. A synchronous online discussion refers to a situation or environment where individuals have to login or access the discussion system at the same time but they may be in different places. Usually they receive messages from each other in real time or in a very short time (since sending messages from one place to another takes time). An asynchronous online discussion environment, on the other hand, refers to a situation that allows individuals to login any time and any place to post online messages or reply to others. Many educators and researchers believe that asynchronous online discussion is a more useful tool to support learning. Some of the reported advantages of using asynchronous online discussion include the convenience of communication between students and between students and teachers, promotion of student reflection, higher level learning, as well as clear and precise thinking (e.g., Newman, Webb \& Cochran, 1997; Romiszowski \& Mason, 2004). Due to the perceived benefits of asynchronous online discussion, many schools and universities integrate it with their face to face tutorials or lectures (Cheung \& Hew, 2008). Some researchers refer this integration or mixture as the blended learning approach. 
While an asynchronous online discussion environment can foster certain benefits, we agree with Cheung and Hew (2008) that such benefits can only be realised if students are willing to take part in the discussion. Many studies have been conducted to find out what factors that could affect the participation rate of students in an asynchronous online discussion environment (e.g., Hew, Cheung \& Ng, 2009). These factors include the design of the discussion activity (Guzdial \& Turns, 2000; Poscente \& Fahy, 2003; Master \& Oberprieler, 2004; Dennen, 2005), participants' knowledge about the discussion topic (Fung, 2004; Hewitt, 2005), and the behaviour of other participants (Feenberg, 1987; Bodzin \& Park, 2000; Hewitt \& Teplovs, 1999; Jeong, 2004; Zhao \& McDougall, 2005). In recent years, we found some research studies which examined how student facilitators' facilitation skills may influence the online discussion (Chan, Hew \& Cheung, 2009; Ng, Cheung \& Hew, 2009). We believe that even though the facilitators need to have the appropriate facilitation skills, it is equally important that they also have the appropriate habits of mind to facilitate the asynchronous online discussions. In this study, we explore the habits of mind of the facilitators in an asynchronous online discussion environment.

\section{Research questions}

In this study, we analyse the following five habits of mind of the facilitators: awareness of own thinking, accurate and seeks accuracy, open minded, taking a position when the situation warrants it, and sensitive to others. Based on these habits of mind, the following research questions will be addressed:

1. To what degree is each of the aforementioned habits of mind exhibited by the facilitators during the online discussion?

2. What types of habits of mind are prominent in groups that have a high degree of learner participation in the discussion? Here learner participation is estimated from the quantity of messages posted by the learners (excluding the facilitators).

\section{Literature review}

We posit that facilitation skills and habits of mind of the facilitators are two major factors that could influence the participants to participate in asynchronous online discussion environment. It is hard to believe that facilitators can facilitate well if they merely have the skills but not the appropriate habits of mind to facilitate. In the last fifteen years, researchers have largely focused their attention on the facilitation skills of the facilitators (Hewitt, 2005; Master \& Oberprieler, 2004; Jung, Choi, Lim \& Leem, 2002; Tagg\& Dickinson, 1995) rather than the habits of mind of the facilitators (Hew \& Cheung, in press; Cheung \& Hew, 2008). In the following section, we will explore the meaning of habits of mind, review some of the influential proponents in the field of habits of mind, and then focus our review on five specific habits of mind of the facilitators.

First, what are habits of mind? Habits of mind may be defined as the natural tendency of an individual to act and think when he or she faces an issue or a problem (Costa \& Kallick, 2000; Marzano et al., 1993). In simple words, habits of mind refer to the affective dimension of thinking (Neo \& Cheung, 2007). While some scholars used the term habits of mind (Marzano, Pickering \& McTighe, 1993; Costa \& Kallick, 2000), others have used other terms such as habits of thought (Dewey, 1933), and thinking dispositions (Ennis, 1987; and Facione, Sanchez, Facione,\& Gainen, 1995). Despite the various 
names used, a closer examination of the terms suggests that they are quite similar in spirit (Tishman, 2000).

There are currently two major proponents of habits of mind. They are Marzano, Pickering and McTighe (1993), and Costa and Kallick (2000). Marzano, Pickering and McTighe (1993, pp. 88-93) suggested 15 habits of mind: aware of own thinking, makes effective plans, aware of and use necessary resources, evaluate the effectiveness of own actions, sensitive to feedback, accurate and seeks accuracy, clear and seeks clarity, open minded, restrains impulsivity, takes a position when situation warrants it, sensitive to the feelings and level of knowledge of others, engages intensely in tasks even when answers or solutions are not immediately apparent, pushes the limits of own knowledge and ability, generates trusts, maintains own standards of evaluation, and generates new ways of viewing a situation outside the boundaries of standard convention.

Costa and Kallick (2000), on the other hand, proposed 16 habits of mind: persisting, managing impulsivity, listening with understanding and empathy, thinking flexibly thinking about your thinking, striving for accuracy and precision, questioning and problem posing, applying past knowledge to new situations, thinking and communicating with clarity and precision, gathering data through all senses, creating, imagining, and innovating, responding with wonderment and awe, taking responsible risks, finding humor, thinking interdependently, and remaining open to continuous learning.

We agree with Tishman's (2000) view that although it seems that the two proponents offer various habits of mind, some of the habits are very similar. Some examples are: "open minded" (Marzano et al., 1993) and "remaining open to continuous learning" (Costa \& Kallick, 2000); "accurate and seeks accuracy" (Marzano et al., 1993) and "striving for accuracy and precision" (Costa \& Kallick, 2000); as well as "clear and seeks clarity" (Marzano et al., 1993) and "thinking and communicating with clarity and precision" (Costa \& Kallick, 2000).

In our study, we explore the following five specific habits of mind: awareness of own thinking, accurate and seeks accuracy, open minded, takes a position when the situation warrants it, and sensitivity to others. To have clear indicators for the five habits of mind, we adopted Cheung and Hew's (2008) indicators of those habits. They modified the original rubrics of the habits of mind from Marzano et al (1993), deriving the indicators of the five habits of mind shown in Table 1.

\section{Methodology}

According to Yin (2006 p. 112), "The case study method is best applied when research addresses descriptive or explanatory questions and aims to produce a firsthand understanding of people and events". The key purpose of this study is to help us gain an in depth understanding of a situation (Merriam, 2001) - facilitators' habits of mind in an asynchronous online discussion environment - rather than to generate grand predictions. We used a two case studies design approach because such a design could strengthen the findings of our study (Yin, 2006). These two cases were chosen as replications of each other with some minor differences. 
Table 1: Indicators of five habits of mind (after Cheung \& Hew, 2008)

\begin{tabular}{|c|c|}
\hline Habits of mind & Indicators \\
\hline $\begin{array}{l}\text { Is aware of own } \\
\text { thinking }\end{array}$ & $\begin{array}{l}\text { - Describes the thoughts he or she uses when } \\
\text { faced with a task, problem, or question. } \\
\text { Describe how an awareness of own thinking } \\
\text { helps me to improve the task. }\end{array}$ \\
\hline $\begin{array}{l}\text { Is accurate and seeks } \\
\text { accuracy }\end{array}$ & $\begin{array}{l}\text { - } \quad \text { Pays attention to detail when appropriate. } \\
\text { - } \quad \text { Recognise inst relevant sources. } \\
\text { - } \quad \text { Corrects inaccuracies quickly. } \\
\text { identified errors, but add not only clear up the }\end{array}$ \\
\hline Is open minded & $\begin{array}{l}\text { - } \quad \text { Considers alternative views. } \\
\text { - }\end{array}$ \\
\hline $\begin{array}{l}\text { Takes a position when } \\
\text { the situation warrants it }\end{array}$ & $\begin{array}{l}\text { - Takes a position that is related to the circumstances. } \\
\text { - } \quad \text { Provide justification for the position. }\end{array}$ \\
\hline Is sensitive to others & $\begin{array}{l}\text { - Show concerns about others' feelings. } \\
\text { - } \quad \text { Show concerns about others' level of knowledge. } \\
\text { - Encourages respect for individual differences. }\end{array}$ \\
\hline
\end{tabular}

For the first case, we chose the Design of Asynchronous Online Discussion course (Case A) in the Master of Arts - Instructional Design and Technology (MAIDT) program. Thirteen graduate students ( 3 females and 10 males) participated in the course. Students were taught how to design asynchronous online discussion activities during the face-to-face tutorials. They were then asked to upload their design drafts of their asynchronous online discussion activity onto Blackboard for their classmates to critique. The main purpose of the online discussion activity was to allow the students to be the facilitator of their online discussion forums. At the same time, the students were also participants, identifying problems of their classmates' projects, making suggestions, and giving comments on other people's suggestions, in order to improve the quality of the projects.

In order to verify the findings of the first case, we partially redesigned the first case and conducted the second study. A Multimedia Design course (Case B) was selected. Similar to Case A, the Multimedia Design course was from the same MAIDT program. Sixteen graduate students ( 5 females, and 11 males) enrolled in the course. Students were taught various multimedia design concepts and guidelines during the face to face tutorials. They were asked to upload their design drafts of their multimedia story board onto Blackboard for their classmates to critique.

We selected the two cases according to the following criteria. First, all the online discussion forums were facilitated by students. Second, the courses used "blended approach". Third, the same instructor taught both courses. Fourth, both courses were in the same program. In our study, we chose both courses from the Master of Arts program. This was to minimise the risk of possible confounding variables due to the students' academic level. Fifth, the task nature was the same for both Case A and Case $\mathrm{B}$ - an ill-structured design problem. All the students were asked to solve design problems through the online discussion. Sixth, the students utilised the same software (i.e., Blackboard) for the online discussions.

However, there were a few differences between the first case and the second case. First, the duration of the online discussion for those two courses was not the same. It 
was two weeks for Case A and eight days for Case B. Second, credits were given to students who participated in the online discussion forums in Case A, but not Case B. Third, there was one student facilitator per forum in Case A while there were two student facilitators per forum in Case B.

\section{Data analysis}

To address the first research question, "To what degree is each of the aforementioned habits of mind exhibited by the facilitators during the online discussion?", we used a content analysis method on all the online discussion transcripts posted by the student facilitators. Our unit of analysis was the thematic unit, which was the individual theme or idea conveyed by the facilitators. We examined whether any of the following habits of mind (awareness of own thinking, accurate and seeks accuracy, open minded, taking a position when the situation warrants it, and sensitive to others) were exhibited by the facilitators. An independent coder was trained to code the entire data. To determine the consistency of the coding, the first author coded about $10 \%$ of the facilitators' online postings. These $10 \%$ of data were randomly selected from the entire facilitators' postings. Overall, the percent agreement was $90 \%$.

To address the second research question, "What are the prominent habits of mind displayed by facilitators in groups that have high degree of learner participation in the discussion?", we evaluated the transcripts in terms of the quantity of messages posted by the learners (excluding the facilitators') in each forum. We ranked the participants' postings (excluding facilitators' postings) and chose the top $30 \%$ of the forums which had the highest number of participants' postings. We analysed the transcripts of the five habits of mind according to Cheung and Hew's modified version (see Table 1).

\section{Results}

1. To what degree is each of the aforementioned habits of mind exhibited by the facilitators during the online discussion?

For Case A, "Aware of thinking" was the most often displayed habit of mind exhibited by the facilitators; while "Open minded" was the most often displayed habit of mind in Case B. It seems that Case B confirmed the findings from Case A in that the two most often displayed habits of mind were "Aware of thinking" and "Open minded", although the order was not the same. The details of all the five habits of mind are shown in Table 2.

Table 2: Habits of mind exhibited by all facilitators during the online discussion

\begin{tabular}{|l|c|c|c|c|}
\hline \multirow{2}{*}{ Displayed habits of mind } & \multicolumn{2}{c|}{ Case A } & \multicolumn{2}{c|}{ Case B } \\
\cline { 2 - 5 } & Frequency & $\%$ & Frequency & $\%$ \\
\hline Is aware of own thinking. & 73 & $52 \%$ & 65 & $40 \%$ \\
\hline Is accurate and seeks accuracy. & 12 & $8 \%$ & 13 & $8 \%$ \\
\hline Is open minded. & 48 & $34 \%$ & 70 & $43 \%$ \\
\hline $\begin{array}{l}\text { Takes a position when the situation } \\
\text { warrants it. }\end{array}$ & 7 & $5 \%$ & 14 & $8 \%$ \\
\hline Is sensitive to others. & 2 & $1 \%$ & 2 & $1 \%$ \\
\hline
\end{tabular}


2. What types of habits of mind are prominent in groups that have high degree of participation in the discussion?

After ranking the participants' postings (excluding facilitators' postings), we chose the top $30 \%$ of the forums, which had the highest number of participants' postings. We examined the facilitators' habits of mind in those discussion forums. For Case A, it was "Aware of thinking" and "Open minded" as the first and the second most often exhibited habits of mind, by the facilitators' in the online forums. For Case B, "Open minded" and "Aware of thinking" were the first and second most often exhibited habits of mind, by the facilitators. The findings are summarised in Table 3.

Table 3: Habits of mind exhibited by the facilitators who had the higher participants' posting (ie top 30\%)

\begin{tabular}{|l|c|c|c|c|}
\hline \multirow{2}{*}{ Displayed habits of mind } & \multicolumn{2}{c|}{ Case A } & \multicolumn{2}{c|}{ Case B } \\
\cline { 2 - 5 } & Frequency & $\%$ & Frequency & $\%$ \\
\hline Is aware of own thinking & 33 & $64 \%$ & 27 & $32 \%$ \\
\hline Is accurate and seeks accuracy & 3 & $6 \%$ & 12 & $14 \%$ \\
\hline Is open minded & 12 & $24 \%$ & 40 & $47 \%$ \\
\hline $\begin{array}{l}\text { Takes a position when the situation } \\
\text { warrants it. }\end{array}$ & 3 & $6 \%$ & 5 & $6 \%$ \\
\hline Is sensitive to others & 0 & $0 \%$ & 1 & $1 \%$ \\
\hline
\end{tabular}

\section{Discussion}

Overall, according to our finding, facilitators tended to exhibit "Aware of thinking" and "Open minded" more often than the other habits of mind in both cases. When we zoomed into the top $30 \%$ of the forums in terms of learners' participation, the facilitators for those forums also tended to exhibit "Aware of thinking" and "Open minded" habits of mind more often than the other habits. When we interviewed the students, one of them told us that when the facilitators' exhibited "Aware of thinking" in the online postings, it helped her to have a better understanding of what the discussion was about. This in turn motivated her to participate in the online discussion actively.

Student A: When the facilitator is aware of his own thinking, he will give the participants a clear idea about the issues for discussion or the discussion direction. As a result, I will be more involved by providing more comments and feedback of the discussed issues. There were times that I did not understand what the facilitators were thinking by reading the posting. If I did not understand what the facilitators expected the participants to contribute in the online discussion, then I found it very difficult for me to respond to their postings.

In addition, another student pointed out the importance of the "Open minded" habit exhibited by the facilitator in the online postings.

Student B: I will participate more actively when then the facilitator was open minded. This showed the facilitator was willing to accept opinion from others without being biased.

When we compared the two cases, there was a higher percentage of the open minded habit in Case B. One plausible reason for this is that no credit was given to the students in Case B; hence the facilitators had to make a greater effort in encouraging 
participants to contribute in the online discussion forum. As a result, the facilitators exhibited more open minded habits of mind so that they could welcome ideas and suggestions from the participants without being biased.

There was another interesting finding from our interview with Student B. He exhibited more "accuracy and seek accuracy" habits of mind when he served as a participant in other people's forums. This was because he believed it was the participants' responsibility, rather than the facilitators' responsibility, to provide accurate information for others. It could be that there were other participants who had the same belief as Student B. In such a case, we could understand why the exhibited facilitators' "accurate and seeks accuracy" habits of mind did not happen as often as "Open minded" and "Aware of own thinking".

Student B: I believe it is the participants' responsibility to provide accurate information for the group members; however, the facilitator's role should encourage group members to participate in the online discussion.

We believe some facilitators did not want to "take a position" because it might cut off contribution of ideas from the participants of the online discussions, as explained by one student facilitator:

Student A: I feel that when I take a certain position, the other participants would not want to contribute further. This is because when a facilitator takes a position, he is implying to other people that he or she has already decided to act on a certain idea or suggestion. This discourages other participants from voicing any further comments, especially from those who have yet to contribute their viewpoints.

Another plausible explanation as to why other students are reluctant to contribute to discussions when the facilitators have taken a certain position may be due to the personality of Asian students, who may worry about offending people, especially in situations when their opinions conflict with that of the facilitators (Zhao \& McDougall, 2005).

Most of the facilitators did not show the habit of "sensitive to others" in the online discussion forums. One of the students shared with us in the interview that:

Even though I did not exhibit sensitivity to others, it did not mean I was not sensitive to them. Probably I was more focused on the discussion task, rather than sensitive to others in our relationship.

Other studies (e.g., Hew \& Hara, 2007; Jonassen \& Kwon, 2001) also have suggested that individuals tended to be more task oriented in the online discussion context and less engaged in social-emotional activities. Another possible reason may be the facilitators did not know how to show sensitivity to others in the online discussion context.

\section{Conclusion}

In this study, we examined the habits of mind of the facilitators when they conducted online discussion. We understand that the design of the online discussion activities may influence the facilitators' exhibited habits of mind in an online discussion environment. In our case, the facilitators were the owners of the design of the projects being discussed. Within this context, "Aware of thinking" and "opened minded" were 
the most exhibited habits of mind of the facilitators. However, the findings may be different when the context is different.

Future research could investigate the influence of the facilitators' habits of mind on the quality of the online discussions. The quality of online discussions may be assessed by examining the depth of cognitive processes such as creative thinking, and critical thinking (see Hew \& Cheung, 2003) exhibited by the participants. It would also be interesting to adapt this research to other online environments in other subject areas that are facilitated by academic staff, to see whether our findings are applicable. To provide a more complete answer to the question "Do the facilitators' habits of mind influence the degree of learners' participation?", future studies could go further into comparing the facilitators' habits of minds for groups with high, medium, and low levels of learners' participation.

\section{Acknowledgment}

Preliminary findings of this study were presented at the annual conference of the Australasian Society for Computers in Learning in Tertiary Education (ASCILITE) in Melbourne, Australia, 2008.

\section{References}

Bodzin, A. \& Park, J. (2000). Factors that influence asynchronous discourse with preservice teachers on a public, web-based forum. Journal of Computing in Teacher Education, 16(4), 22-30.

Bullen, M. (1998). Participation and critical thinking in online university distance education. Journal of Distance Education, 13(2). http: / / 168.144.129.112/ Articles/Participation\%20and $\%$ 20Critical $\% 20$ Thinking $\% 20$ in $\%$ 20Online $\%$ 20University $\% 20$ Distance $\% 20$ Education.rtf

Chan, C. C. J., Hew, K. F., \& Cheung, W. S (2009). Asynchronous online discussion thread development: Examining growth patterns and peer-facilitation techniques. Journal of Computer Assisted Learning, 25(5), 438-452.

Cheung, W. S. \& Hew, K. F. (2008). Examining facilitators' habits of mind and learners' participation. In Hello! Where are you in the landscape of educational technology? Proceedings ascilite Melbourne 2008. http:/ / www.ascilite.org.au/conferences/melbourne08/procs/cheung.pdf

Cheung, W. S. \& Hew, K. F. (2005). How can we facilitate students' in-depth thinking and interaction in an asynchronous online discussion environment? A case study. Proceedings of the Association for Educational Communications and Technology, USA, 28, 114-121.

Cheung, W. S. \& Hew K. F. (2004). Evaluating the extent of ill-structured problem solving process among pre-service teachers in an asynchronous online discussion and reflection log learning environment. Journal of Educational Computing Research, 30(3). 197-227.

Choitz, P. \& Lee, D. (2006). Designing asynchronous, text-based computer conferences. Performance Improvement Quarterly, 19(3), 55-71.

Cifuentes, L., Murphy, K. L., Segur, R. \& Kodali, S. (1997). Design considerations for computer conferences. Journal of Research on Computing in Education, 30(2), 177-201.

Costa, A. L. \& Kallick, B. (2000). Assessing the habits of mind. In A. L. Costa \& B. Kallick (Eds.), Assessing and reporting on habits of mind, pp. 29-53. Alexandria, VA: Association for Supervision and Curriculum Development.

Dennen, V. P. (2005). From message posting to learning dialogues: Factors affecting learner participation in asynchronous discussion. Distance Education, 26(1), 127-148. 
Ennis, R. H. (1987). A taxonomy of critical thinking dispositions and abilities. In J. B. Baron \& R. S. Sternberg (Eds.), Teaching thinking skills: Theory and practice (pp. 9-26). New York: Freeman.

Facione, P. A., Sanchez, C. A., Facione, N. C. \& Gainen, J. (1995). The disposition toward critical thinking. Journal of General Education, 44(1), 1-25.

Facione, P. A., Facione, N. C. \& Giancarlo, C. F. (1997). The motivation to think in working and learning. In E. Jones (Ed.), Preparing competent college graduates: Setting new and higher expectations for student learning (pp. 67-79). San Francisco, CA: Jossey-Bass.

Feenberg, A. (1987). Computer conferencing and the humanities. Instructional Science, 16(2), 169186.

Fung, Y. Y. H. (2004). Collaborative online learning: Interaction patterns and limiting factors. Open Learning, 19(2), 135-149.

Fung, A. C. W., Fu, F. H. K. \& Cheung, W. S. (2005). The application of web-based teaching and learning in tertiary institution - A Case Study in Hong Kong. New Horizons in Education, 51, 68-80.

Ganeva, I. (1999). Native and non-native speakers' participation in educational asynchronous computer conferencing: A case study. Unpublished Masters thesis. Ontario Institute for Studies in Education, University of Toronto. [verified 28 Feb 2010; $8.8 \mathrm{MB}$ ] http: / / www.collectionscanada.ca/obj/ s4 / f2 / dsk1 / tape7 / PQDD_0005/MQ45959.pdf

Guzdial, M. (1997). Information ecology of collaborations in educational settings: Influence of tool. In R. Hall, N. Miyake, \& N. Enyedy (Eds.), Proceedings of Computer-Supported Collaborative Learning (pp. 83-90). Toronto, Canada: Lawrence Erlbaum Associates.

Guzdial, M. \& Turns, J. (2000). Effective discussion through a computer-mediated anchored forum. Journal of the Learning Sciences, 9(4), 437-469.

Harmon, S. W. \& Jones, M. (2000). The five levels of web use in education: Factors to consider in planning online courses. Educational Technology, 39(6), 28-32.

Hew, K. F. \& Cheung, W. S. (2003). Evaluating the participation and quality of thinking of preservice teachers in an asynchronous online discussion environment: Part 2. International Journal of Instructional Media, 30(4), 355-366.

Hew, K. F. \& Cheung, W. S. (in press). Student facilitators' habits of mind and their influences on higher-level knowledge construction occurrences in online discussions: A case study. Innovations in Education and Teaching International Journal.

Hew, K. F., Cheung, W. S. \& Ng, C. S. L. (2009). Student contribution in asynchronous online discussion: A review of the research and empirical exploration. Instructional Science. Doi: $10.1007 / \mathrm{s} 11251-008-9087-0$.

Hew, K. F. \& Hara, N. (2007). Empirical study of motivators and barriers of teacher online knowledge sharing. Educational Technology Research and Development, 55, 573-595.

Hewitt, J. (2005). Toward an understanding of how threads die in asynchronous computer conferences. Journal of the Learning Sciences, 14(4), 567-589.

Hewitt, J. \& Teplovs, C. (1999). An analysis of growth patterns in computer conferencing threads. In C. Hoadley \& J. Roschelle (Eds.), Proceedings of the Computer Support for Collaborative Learning (pp. 232-241). Palo Alto, CA: Stanford University Press.

Jeong, A. (2004). The combined effects of response time and message content on growth patterns of discussion threads in computer-supported collaborative argumentation. Journal of Distance Education, 19(1), 36-53.

Jonassen, D. H. \& Kwon, H. I. (2001). Communication patterns in computer-mediated vs. face-toface group problem solving. Educational Technology Research and Development, 49(1), 35-51.

Jung, I., Choi, S., Lim, C. \& Leem, J. (2002). Effects of different types of interaction on learning achievement, satisfaction and participation in web-based instruction. Innovations in Education and Teaching International, 39(2), 153-162. 
Marzano, R. J., Pickering, D. J. \& McTighe, J. (1993). Assessing student outcomes: Performance assessment using the dimensions of learning model. Alexandria, VA: Association for Supervision and Curriculum Development.

Masters, K. \& Oberprieler, G. (2004). Encouraging equitable online participation through curriculum articulation. Computers $\mathcal{E}$ Education, 42, 319-332.

Merriam, S. B. (2001). Qualitative research and case study applications in education. San Francisco: Jossey-Bass.

Murphy, E. \& Coleman, E. (2004). Graduate students' experiences of challenges in online asynchronous discussions. Canadian Journal of Learning and Technology, 30(2). http: / / www.cjlt.ca/index.php/cjlt/article/view/128/122

Neo, C. E. \& Cheung, W. S. (2005). The impact of directed viewing-thinking activity on students' critical thinking: Part II. New Horizons in Education, 52, 80-90.

Newman, D. R., Johnson, C., Webb, B. \& Cochrane, C. (1997). Evaluating the quality of learning in computer supported cooperative learning. Journal of the American Society of Information Science, 48, 484-495.

Ng, C. S. L., Cheung, W. S. \& Hew, K. F. (2009). Sustaining asynchronous online discussions: Contributing factors and peer facilitation techniques. Journal of Educational Computing Research, 41(4), 477-511.

Palloff, R. \& Pratt, K. (1999). Building learning communities in cyberspace: Effective strategies for the online classroom. San Francisco: Jossey-Bass.

Poscente, K. R. \& Fahy, P. J. (2003). Investigating triggers in CMC text transcripts. The International Review of Research in Open and Distance Learning, 4(2). http: / / www.irrodl.org/index.php/irrodl/article/view / 141/221

Tagg, A. C. \& Dickinson, J. A. (1995). Tutor messaging and its effectiveness in encouraging student participation on computer conferences. Journal of Distance Education, 10(2).

Tishman, S. (2000). Why teach habits of mind? In A. L. Costa \& B. Kallick (Eds.), Habits of mind: A developmental series (pp. 41-52). Alexandria, VA: Association for Supervision and Curriculum Development.

Vonderwell, S. \& Zachariah, S. (2005). Factors that influence participation in online learning. Journal of Research on Technology in Education, 38(2), 213-230.

Yin, R. K. (2006). Case study methods. In J. L. Green, G. Camilli \& P. B. Elmore (Eds), Handbook of complementary methods in education research (pp.111-122), Washington DC: Lawrence Erlbaum Associates, Inc.

Zhao, N. \& McDougall, D. (2005). Cultural factors affecting Chinese students' participation in asynchronous online learning. In G. Richards (Ed.), Proceedings of World Conference on Elearning in corporate, government, healthcare, and higher education 2005 (pp. 27232729).Chesapeake, VA: AACE.

Associate Professor Wing Sum Cheung

Learning Sciences \& Technologies Academic Group

National Institute of Education, Nanyang Technological University, Singapore

Email: wingsum.cheung@nie.edu.sg

Assistant Professor Khe Foon Hew

Learning Sciences \& Technologies Academic Group

National Institute of Education, Nanyang Technological University, Singapore

Email: khefoon.hew@nie.edu.sg 